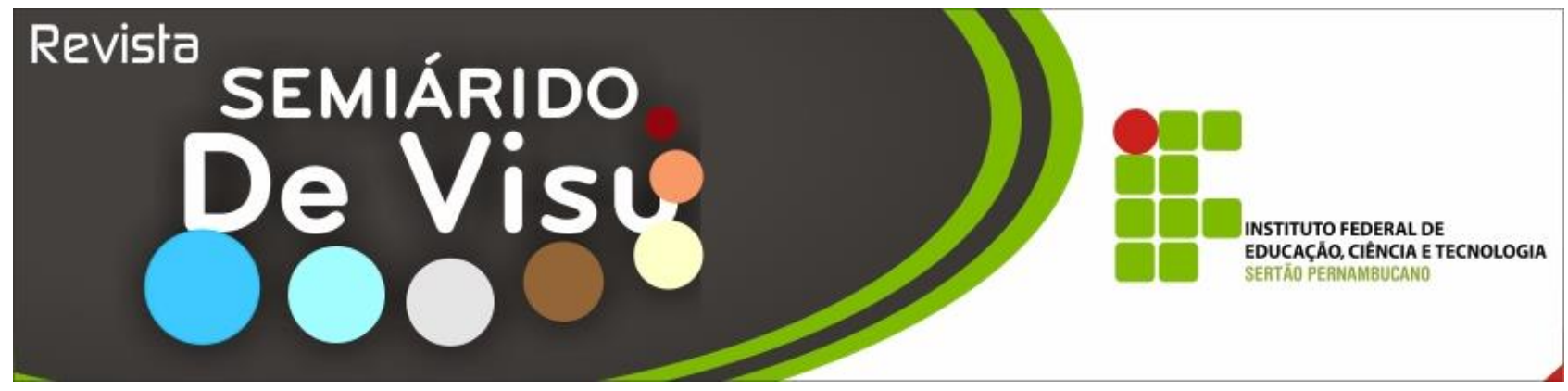

\title{
Agrofísica: utilização de embalagens reutilizáveis para controlar a temperatura sobre o cultivo da alface
}

\author{
Maria Dara Souza Barros ${ }^{1}$, Marcelo de Campos Pereira ${ }^{2}$, Eriverton da Silva Rodrigues ${ }^{3}$, Rômulo \\ Sátiro de Medeiros ${ }^{4}$, Edilaine Pereira de Sousa ${ }^{5}$, Tetisuelma Leal Alves ${ }^{6}$ \\ 1,2,3,4,5,6Instituto Federal do Sertão Pernambucano - campus Salgueiro. BR 232, Km 508, sentido Recife, Zona Rural - Salgueiro - \\ Pernambuco - Brasil. CEP: 56000-000 / Telefone: (87) 3421-0050 / E-mail: darabarros.ta@ gmail.com¹, marcelo.pereira@ ifsertao- \\ pe.edu.br ${ }^{2}$, eriverton.rodrigues@ifsertao-pe.edu.br ${ }^{3}$, romulo.medeiros@ifsertao-pe.edu.br ${ }^{4}$, edilaine.pereira@ ifsertao-pe.edu.br ${ }^{5}$, \\ tetisuelma.leal@ifsertao-pe.edu.br ${ }^{6}$.
}

\begin{abstract}
RESUMO: Realizou-se esta pesquisa no sertão central pernambucano em que há forte incidência da radiação solar, o que prejudica o cultivo de determinadas plantas. Devido a isso, foi feito experimento com a alface, reutilizando embalagens para controlar a temperatura. Assim, utilizou-se uma área de $1,0 \mathrm{~m}^{2}$ por unidade experimental onde foram implantadas duas mudas desta olerícola que se desenvolveu melhor que convencionalmente. A diferença de temperatura foi estudada através de sombreamento obtido a partir de embalagens como leite longa e recipientes similares. As medidas foram realizadas em intervalo de 20 minutos, conforme explicitado nos materiais e métodos. Houve três formas de medições de temperatura: uso de um termômetro infravermelho, um multímetro digital no modo termômetro e um sensor de temperatura LM35, acoplado ao microcontrolador Arduino. O experimento mostrou-se eficiente, na redução da temperatura incidente sobre a planta, pois a mesma esteve sempre inferior em relação a temperatura exterior, proporcionando um melhor desenvolvimento da alface. Porém, para ratificar a eficácia desse método, estão sendo feitas outras repetições para aprimoramento do estudo.
\end{abstract}

Palavras-chave: Radiação solar, sombreamento, luminosidade.

\section{Agrophysics: use of reusable containers to control the temperature on the cultivation of lettuce}

\begin{abstract}
We conducted this research in the central hinterland of Pernambuco where there is high incidence of solar radiation, which damages the cultivation of certain plants. Because of this experiment was made with lettuce, reusing containers to control the temperature. Thus, we used an area of $1.0 \mathrm{~m}^{2}$ per experimental unit where they were implanted two seedlings of vegetable crop that has been developed rather than conventionally. The temperature difference was studied by shading obtained from packaging such as UHT milk and similar containers. The measurements were taken at 20 minute intervals, as detailed in materials and methods. There were three types of temperature measurements: using an infrared thermometer, a digital multimeter on the thermometer mode and a LM35 temperature sensor coupled to the Arduino microcontroller. The experiment proved efficient in reducing the temperature incident on the plant, because it was always lower than the outside temperature, providing a better development of lettuce. However, to confirm the effectiveness of this method, they are being made other repetitions to study improvement.
\end{abstract}

keywords: Solar radiation, shading, luminosity. 
Introdução

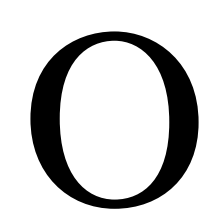

semiárido nordestino é considerado como uma região problemática em termos de recursos naturais, além de estar sujeita à ocorrência de secas frequentes, que contribuem para evidenciar o frágil equilíbrio existente em sua base econômica e social (LIMA e GATTO, 2014).

Dessa forma, o município de Salgueiro, PE, está inserido na unidade geoambiental denominada depressão sertaneja cujo relevo e clima variado fazem com que a região seja caracterizada por áreas de sequeiro com chuvas escassas e mal distribuídas conforme referenciado. Além disso, a vegetação caatinga hiperxerófita com rios temporários e baixos índices pluviométricos, bem como floresta caducifólia, contribuem para a elevação de temperaturas, podendo atingir mais de $36^{\circ} \mathrm{C}$ principalmente nos turnos vespertinos, onde se tem uma forte incidência da radiação solar nas vegetações nesse período do dia. Assim, não é de surpreender que as plantas sejam extremamente sensíveis a luz, respondendo a quantidade, direção, periodicidade e a qualidade da luz (CHANG et al., 2008).

Desse modo, considerando que os vegetais superiores dependem do sol como fonte de energia, sendo que a fotossíntese converte a energia luminosa em energia química, é fundamental desenvolver métodos que minimizem os impactos das elevadas temperaturas nas plantas cultivadas no sertão central, visando uma melhor produtividade.

Em se tratando do cultivo de olerícolas, a luminosidade é um fator relevante, pois a luz tem complexa influência no crescimento, desenvolvimento e produção das plantas. Nesse sentido, o aumento da radiação solar pode aumentar a produção de fotoassimilados e sua disponibilidade para o crescimento da planta e produção de frutos. Porém, a radiação solar quando excessivamente elevada, pode aumentar a taxa transpiratória da planta resultando em fechamento estomático e diminuição da fotossíntese, diminuindo o crescimento e desenvolvimento da planta (OTONI et al,
2012). Já em condições de baixa intensidade de radiação, o alongamento do caule é uma das principais alterações que ocorre nas plantas, podendo haver também o estiolamento da mesma, com presença de folhas maiores e flácidas, além da diminuição da fotossíntese e aumento do ciclo de desenvolvimento (DAN et al., 2010). Cada espécie vegetal ou cultivar possui uma temperatura-base, que pode variar em função da fase fenológica da planta, sendo comum, no entanto, a adoção de um valor médio único para todo o ciclo da cultura, por ser mais fácil a sua aplicação (CAMARGO,1984).

A alface (Lactuca sativa L.) é uma olerícola que se originou de espécies silvestres, ainda atualmente encontradas em regiões de clima temperado, no sul da Europa e na Ásia Ocidental (FILGUEIRA, 2003). É a mais popular das hortaliças folhosas consumidas no mundo e no Brasil, seu consumo ocorre principalmente na forma in natura. Essa espécie apresenta grande importância na alimentação humana, em especial por ser fonte de vitaminas e sais minerais (SILVA et al., 2011). Além disso, a baixa quantidade calórica vem destacando, atualmente a alface na dieta de grande parte da população, como forma de regulação do ganho de peso. Entretanto, seu cultivo apresenta limitações, principalmente em virtude de sua sensibilidade às condições adversas de temperatura, umidade e chuva (GOMES et al., 2005).

Nesta ótica, o cultivo da alface sob estufa agrícola, além de permitir a utilização intensiva da terra e do capital, permite sua produção de maneira controlada, dependendo menos das condições climáticas, havendo melhor aproveitamento dos insumos, possibilitando a distribuição da produção ao longo do ano, além de regularização da oferta e possibilidade de evitar épocas de menor preço e baixa ou nenhuma lucratividade (RODRIGUES et al., 1997).

Por isso, o uso de telas termorrefletoras e difusoras pode contornar o problema mencionado, em razão da sua composição proporcionar mais luz difusa ao ambiente, promovendo redução da temperatura, não 
afetando significativamente os processos relacionados à fotossíntese (POLYSACK, 2009). Sendo assim, o controle parcial das condições edafoclimáticas, possibilita a realização de cultivos em épocas que normalmente não seriam escolhidas para a produção a céu aberto (PURQUERIO \& TIVELLI, 2006).

Dessa maneira, percebe-se que é preciso preocupar-se para que haja melhoria do ambiente e controle da temperatura, incidência da radiação solar e luminosidade na agricultura, principalmente no cultivo de olerícolas como a alface (Lactuca sativa L.) a fim de se proporcionar melhorias no desenvolvimento dessas plantas e, consequentemente, obtenção de maior produtividade.

Mediante o exposto, esta pesquisa visou reutilizar embalagens que seriam descartadas indevidamente para controlar a temperatura incidente sobre o cultivo da alface, monitorando a radiação solar através de uma temperatura equivalente ou, como é comumente chamada, temperatura sol-ar. A implantação da cultura da alface se constituiu debaixo de um dispositivo confeccionado com madeira e embalagens de recipientes como leite longa vida e similares.

\section{Material e métodos}

O projeto foi desenvolvido no IF Sertão-PE, Campus Salgueiro numa área destinada ao cultivo de olerícolas. Para o desenvolvimento da pesquisa, utilizou-se a cultura da alface (Figura 1), a qual foi cultivada de forma orgânica. Para este estudo, foi utilizada uma área de $1,0 \mathrm{~m}^{2}$ por unidade experimental (Figura 2). Em cada unidade experimental foram plantadas duas plantas de alface (Figura 3).

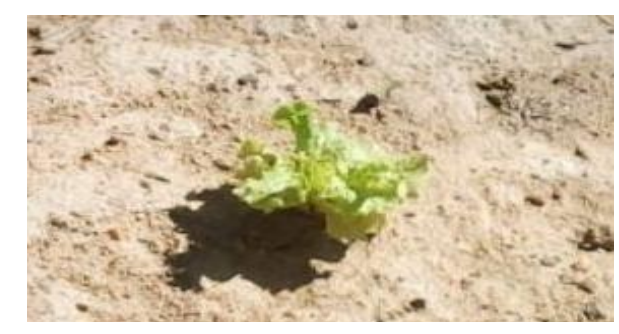

Figura 1. Cultura da alface.

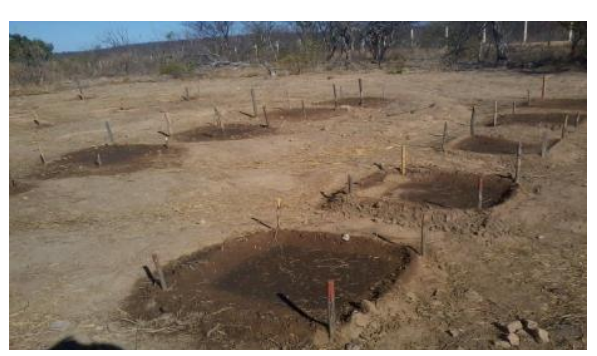

Figura 2. Área experimental.

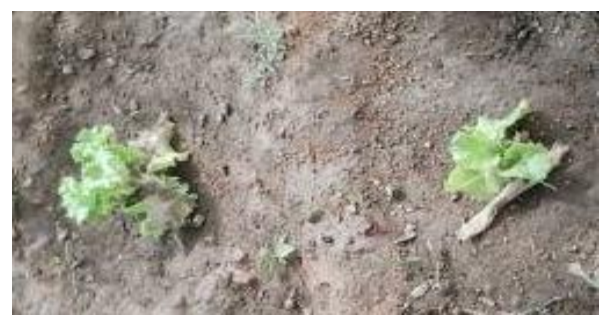

Figura 3. Plantas de alface implantadas na área experimental.

A diferença de temperatura sobre a alface foi estudada através de sombreamento obtido a partir do dispositivo confeccionado com embalagens usadas como recipientes de leite longa vida e similares, além de madeira, que recobria a área experimental (Figura 4 e 5). Tal método configura-se como inovador, considerando que em muitos estudos semelhantes, utilizam-se telas termorrefletoras e difusoras para promover a redução da temperatura. Portanto, a utilização desse dispositivo, mostrou-se promissor, necessitando de mais experimentos para ratificar a eficácia deste método como já estão sendo feitos na instituição.

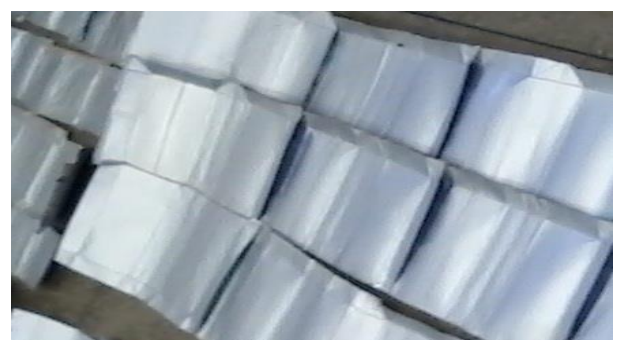

Figura 4. Embalagens longa vida utilizadas na confecção dos protótipos. 
(BARROS et al., 2015)

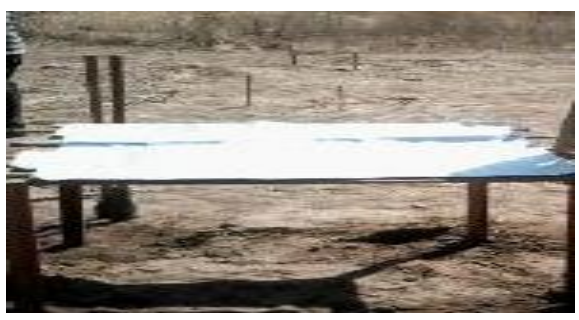

Figura 5. Dispositivo montado na área experimental.

Após a implantação do experimento, as medidas foram realizadas em um intervalo de 20 minutos, entre às 10:00 e 10:20 horas da manhã, sendo obtido um total de 10 medidas, uma a cada 2 minutos. Foram utilizadas três formas de medições de temperatura: uso de termômetro infravermelho, multímetro digital no modo termômetro e sensor de temperatura LM35 acoplado ao microcontrolador Arduino (Figura 6). Foram efetuadas medidas das temperaturas do solo no local, abaixo, acima da área sombreada e da temperatura das folhas da planta. Para cada medida, foi utilizado um equipamento diferente.

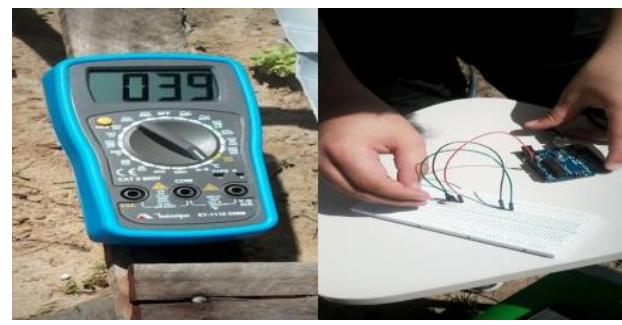

Figura 6. Medidas utilizando o Arduino.

Para as medidas da temperatura realizadas no solo e nas folhas da planta, utilizou-se um termômetro infravermelho, cuja faixa de medição varia de $-30^{\circ} \mathrm{C}$ a $260^{\circ} \mathrm{C}$ e com precisão de $0,1^{\circ} \mathrm{C}$. Para as medidas realizadas sobre a área não sombreada, usou-se um multímetro digital no modo termômetro, com a faixa de medição variando de $-20^{\circ} \mathrm{C}$ a aproximadamente $1000^{\circ} \mathrm{C}$, com precisão de $1^{\circ} \mathrm{C}$. E para as medidas realizadas na área, foi utilizado o sensor de temperatura LM35 junto a placa microcontroladora Arduino, com um precisão de $0,01^{\circ} \mathrm{C}$, ligada a um notebook via um cabo USB. Para as marcações de tempo entre cada medida, foi utilizado como base o tempo de medição do Arduino, ou seja, a cada coleta de temperatura feita pelo Arduino (que foi programado para realizar uma medida a cada 2 minutos) eram realizadas as medidas das temperaturas dos outros pontos.

Para obter melhores resultados, procurou-se fazer as medidas em um dia ensolarado e com altas temperaturas para melhor evidenciar as diferenças de temperatura entre cada ponto do experimento. As medições no solo e nas folhas foram realizadas aproximando o sensor infravermelho a uma distância de aproximadamente $10 \mathrm{~cm}$ do solo e da folha, respectivamente. $\mathrm{O}$ multímetro foi apoiado sobre a estrutura de madeira da estufa, em um ponto onde a luz solar insidia totalmente, sem nenhuma sombra. O sensor LM35 ficou em uma protoboard colocada próxima a planta, em uma área sombreada. $\mathrm{Na}$ protoboard, foram colocados os fios ligando o Arduino ao LM35. O computador foi colocado próximo a estufa e ligado via cabo USB ao Arduino para receber os dados do mesmo.

Dessa forma, a radiação solar foi monitorada através de uma temperatura equivalente ou, como é comumente chamada, temperatura sol-ar.

\section{Resultados e discussão}

Os dados do quadro 1 e da figura 7 apresentam a determinação das temperaturas acima, abaixo do sombreamento, do solo e das folhas. A partir desses dados, pode-se verificar que não ocorreu nenhum dano com a cultura da alface instalada abaixo do protótipo. Através da medição da temperatura, foi observado que o sombreamento oferecido pelo protótipo foi eficiente, pois a temperatura interna ao protótipo esteve em média $10{ }^{\circ} \mathrm{C}$ inferior em relação à temperatura aferida na parte externa (Quadro 1 e Figura 7), proporcionando um maior conforto térmico à cultura. Isso tornou o experimento promissor, visto que Setúbal et. al. (1992) afirmaram que apesar dos inúmeros esforços empregados em trabalhos de melhoramento genético, a produção de alface nas regiões quentes é problemática, resultando em escassez e baixa qualidade do produto e Radin et. al. (2004). Comparando o 
crescimento de cultivares de alface, em estufa e a campo, observaram que as plantas produzidas em ambientes protegidos apresentaram maior produção de matéria fresca. Ainda em relação aos efeitos do sombreamento, Ramos (1995) verificou que o sombreamento da alface proporcionou maior altura de plantas e maior produção de massa seca.

Quando se conduz uma cultura dentro de uma variação ótima de luminosidade com outros fatores favoráveis, a fotossíntese é elevada, a respiração é normal e a quantidade de matéria seca acumulada é alta (BEZERRA NETO et al., 2005). De acordo com Gates (1968), além da exposição à radiação, a temperatura de folha é influenciada por temperatura e umidade do ar e velocidade do vento. Segundo Pilau et. al. (2004), a diferença de temperatura entre folhas acaba por influenciar na resposta estomática e na perda de calor latente por transpiração (GATES, 1968; PILAU et. al., 2004). A temperatura do ar é o elemento climático que exerce maior influência nos processos fisiológicos das plantas de alface, podendo acelerar ou retardar as reações metabólicas, sob condição de temperatura ótima ou inferiores a esta, respectivamente (VIEIRA \& CURY, 1997). Para todas as cultivares de alface, a ocorrência de dias curtos e temperaturas amenas favorecem a etapa vegetativa, sendo estas, inclusive, resistentes a baixas temperaturas e geadas leve (FILGUEIRA, 2003).

Com base nos dados obtidos, foi possível verificar que a planta de alface que não é adaptada a altas temperaturas, característico da nossa região, consegue resistir às condições climáticas locais, podendo atingir elevadas produtividades, mediante o auxílio do dispositivo.

Quadro 1 - Medidas das temperaturas acima, abaixo do sombreamento, do solo e das folhas a intervalos constantes.

\begin{tabular}{|c|c|c|c|c|c|c|c|c|c|c|}
\hline Horários & $10: 00 \mathrm{~h}$ & $10: 02 \mathrm{~h}$ & $10: 04 \mathrm{~h}$ & $10: 06 \mathrm{~h}$ & $10: 08 \mathrm{~h}$ & $10: 10 \mathrm{~h}$ & $10: 12 \mathrm{~h}$ & $10: 14 \mathrm{~h}$ & $10: 16 \mathrm{~h}$ & $10: 18 \mathrm{~h}$ \\
\hline $\begin{array}{l}\text { Temperatura } \\
\text { acima do } \\
\text { sombreamento }\end{array}$ & $36^{\circ} \mathrm{C}$ & $40^{\circ} \mathrm{C}$ & $42^{\circ} \mathrm{C}$ & $42^{\circ} \mathrm{C}$ & $43^{\circ} \mathrm{C}$ & $44^{\circ} \mathrm{C}$ & $45^{\circ} \mathrm{C}$ & $45^{\circ} \mathrm{C}$ & $45^{\circ} \mathrm{C}$ & $46^{\circ} \mathrm{C}$ \\
\hline $\begin{array}{l}\text { Temperatura } \\
\text { abaixo do } \\
\text { sombreamento }\end{array}$ & $33,9^{\circ} \mathrm{C}$ & $34,3^{\circ} \mathrm{C}$ & $33,8^{\circ} \mathrm{C}$ & $33,8^{\circ} \mathrm{C}$ & $34,3^{\circ} \mathrm{C}$ & $34,7^{\circ} \mathrm{C}$ & $34,3^{\circ} \mathrm{C}$ & $33,9^{\circ} \mathrm{C}$ & $34,1^{\circ} \mathrm{C}$ & $34,7^{\circ} \mathrm{C}$ \\
\hline $\begin{array}{l}\text { Temperatura } \\
\text { do solo }\end{array}$ & $32,1^{\circ} \mathrm{C}$ & $31^{\circ} \mathrm{C}$ & $28,3^{\circ} \mathrm{C}$ & $26,8^{\circ} \mathrm{C}$ & $26,9^{\circ} \mathrm{C}$ & $26,7^{\circ} \mathrm{C}$ & $25,8^{\circ} \mathrm{C}$ & $23,7^{\circ} \mathrm{C}$ & $25^{\circ} \mathrm{C}$ & $24,2^{\circ} \mathrm{C}$ \\
\hline $\begin{array}{l}\text { Temperatura } \\
\text { da folha da } \\
\text { alface }\end{array}$ & $31,1^{\circ} \mathrm{C}$ & $28,5^{\circ} \mathrm{C}$ & $26,6^{\circ} \mathrm{C}$ & $23,4^{\circ} \mathrm{C}$ & $23,1^{\circ} \mathrm{C}$ & $20,8^{\circ} \mathrm{C}$ & $19,5^{\circ} \mathrm{C}$ & $21^{\circ} \mathrm{C}$ & $21^{\circ} \mathrm{C}$ & $24,8^{\circ} \mathrm{C}$ \\
\hline
\end{tabular}

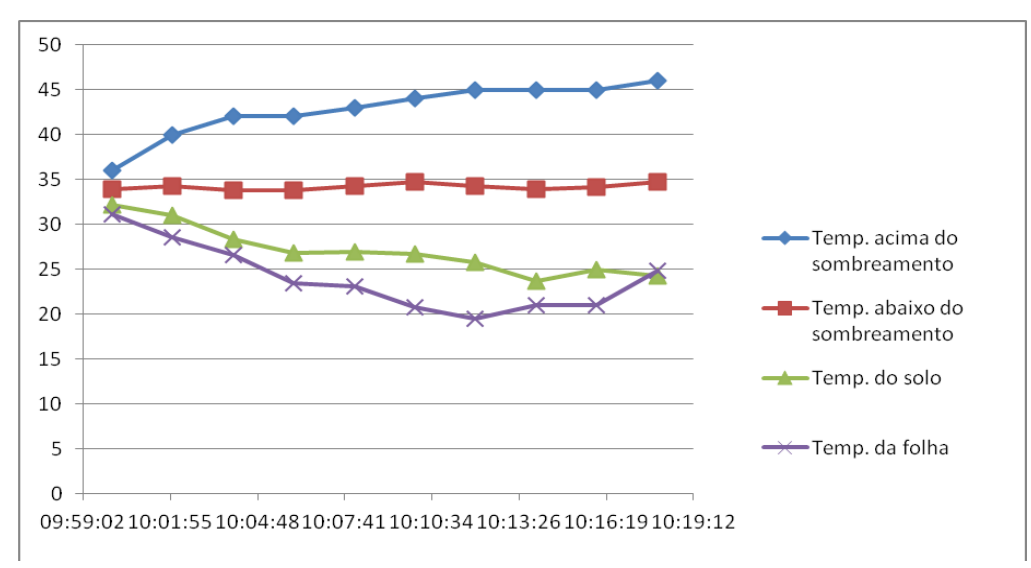

Figura 7. Temperaturas acima, abaixo do sombreamento, do solo e das folhas. 
$\mathrm{O}$ experimento demonstrou-se eficiente tendo em vista que reutilizar embalagens para controlar a temperatura incidente sobre 0 cultivo da alface reduziu a temperatura incidente sobre a planta, pois a mesma esteve sempre inferior em relação a temperatura exterior (em torno de $10^{\circ} \mathrm{C}$ ), proporcionando um melhor desenvolvimento da alface.

Em virtude das temperaturas apresentadas na maior parte do tempo no sertão central de Pernambuco serem maiores que as recomendadas para a cultura da alface, os resultados evidenciam que o cultivo dessa olerícola, através desta técnica é eficaz. Porém, para ratificar a qualidade deste método, estão sendo feitas outras repetições para aprimoramento do estudo.

\section{Referências}

BEZERRA NETO, F.; ROCHA, R.C.C.; NEGREIROS, M.Z.; ROCHA, R.H.; QUEIROGA, R.C.F. Produtividade de alface em função de condições de sombreamento e temperatura e luminosidade elevadas. Horticultura Brasileira, Brasília, v.23, n.2, p.189-192, abr-jun 2005.

CAMARGO, M.B.P. Exigências bioclimáticas e estimativa da produtividade para quatro cultivares de soja no Estado de São Paulo. Piracicaba, 1984, 96p. Tese (Mestrado em Agrometeorologia) - Curso de Pós-raduação em Agronomia, Escola Superior de Agricultura "Luiz de Queiroz", Universidade de São Paulo, 1984.

CHANG, X.; ALDERSON, P. G.; WRIGHT, C. J. Solar irradiance level alters the growth of basil (OcimumbasilicumL.) and its content of volatile oils. Environmental and Experimental Botany, v.63, p.216 223, 2008.

DAN, H.A.; CARRIJO, M.S.; CARNEIRO, D.F.; COSTA, K.A.de P.; SILVA, A.G. Desempenho de plantas sorgo granífero sobre condições de sombreamento. Acta Scientiarum Agronomy, Maringá, v.32, n.4, p.675-679, 2010.
FILGUEIRA, F. A. R. Novo manual de olericultura: agrotecnologia moderna na produção e comercialização de hortaliças. $2^{\mathrm{a}}$ ed., UFV, 2003.

GATES, D. M. Transpiration and leaf temperature. Ann. Rev. Plant Physiol., Palo Alto, v. 19, p. 211-239, 1968.

GOMES, T.M.; BOTREL, T.A.; MODOLO, V.A.; OLIVEIRA, R.F. Aplicação de $\mathrm{CO} 2$ via água de irrigação na cultura da alface. Horticultura Brasileira, Brasília, v. 23, n. 2, p 316-319, abr-jun 2005.

LIMA, J. P. R.; GATTO, M. F. A economia do Semiárido de Pernambuco: ainda "sem produção"?. Economia e Desenvolvimento, Recife, v. 13, n. 1, 2014.

OTONI, B. S.; MOTA. W. F.; BELFORT, G. R.; SILVA, A.R.S.; VIEIRA, J. C.B.; ROCHA, L. de S. Produção de híbridos de tomateiro cultivados sob diferentes porcentagens de sombreamento. Revista Ceres, Viçosa, v.59, n.6, p.816-825, 2012.

PILAU, F. G. BONNECARRÈRE, R. A. G; NETO, D. D.; MEDEIROS, S. L. P.; MANFRON, P. A. Condutância foliar à difusão de vapor e transpiração em função da temperatura da folha de plantas de alface sob cultivo hidropônico. Revista Cientifica Rural, Bagé, v. 9, n. 2, p. 106-112, 2004.

\section{POLYSACK INDÚSTRIAS Ltda. Malhas termorrefletoras aluminizadas. Disponível em: \\ <http://www.polysack.com/index.php?page_id =744> Acesso em: 20/05/2016.}

PURQUERO L.F.V.; TIVELLI S.W. Manejo do ambiente em cultivo protegido. Informações Tecnológicas, Campinas, 2006. In: IAC, 2006. Disponível em:

$<$ http://www.iac.sp.gov.br/Tecnologias/MANEJ O_Cultivo_Protegido/Manejo_Cultivo_protegi do.httm> Acesso em: 20/05/2016. 
(BARROS et al., 2015)

RADIN, B.; JÚNIOR, C.R.; MATZENAUER, R.; BERGAMASCHI, H. Crescimento de cultivares de alface conduzidas em estufa e a campo. Horticultura Brasileira, Brasília, DF, v.22, n.2, p.178-181, 2004.

RAMOS, J.E.L. Sombreamento e tipos de recipientes na formação de mudas e produção em alface. 1995. 56 f. (tese mestrado) - ESAM, Mossoró-RN.

REIS, J.M.R., RODRIGUES, J.F., REIS, M.A. Comportamento da alface crespa em função do parcelamento da adubação de cobertura. Gl. Sci. Technol., Rio Verde, v. 05, n. 02, p.24 30, 2012.

RODRIGUES, A.B.; MARTINS, M.I.E.G.; ARAÚJO, J.C.C. Avaliação econômica da produção de alface em estufa . Informações Econômicas, São Paulo, v.27, n.1, p.27-33, 1997.

SETÚBAL, J.W.; SILVA. A.M.R. Avaliação do comportamento de alface de verão em condições de calor no município de TeresinaPI. Horticultura Brasileira, Brasília, DF, v.10, n.1, p.69, 1992.

SILVA, E. M. N. C. P. et al. Qualidade de alface crespa cultivada em sistema orgânico, convencional e hidropônico. Horticultura Brasileira, v. 29, n. 02, p. 242-245, 2011.

SOUZA, JO; DALPIAN T; BRAZ, LT. Desempenho de genótipos de alface crespa em cultivo protegido. Horticultura Brasileira, v.27: p.234-236, 2009.

VIEIRA, V.C.R.; CURY, D.M.L. Graus-dias na cultura do arroz. In: Congresso brasileiro de Agrometeorologia. Piracicaba-SP, 1997, Anais. Piracicaba: SBA, 1997. p.47-49. 